\title{
Supraventriculaire tachycardie met isoritmische atrioventriculaire dissociatie bij een labrador-retriever
}

\author{
Supraventricular tachycardia with isorhythmic atrioventricular dissociation \\ in a Labrador retriever
}

${ }^{1}$ A. van Loon, ${ }^{1}$ V. Liekens, ${ }^{2}$ D. Binst, ${ }^{1}$ D. Paepe, ${ }^{3}$ B. Houdellier, ${ }^{1}$ P. Smets
${ }^{1}$ Vakgroep Kleine Huisdieren, Faculteit Diergeneeskunde, Universiteit Gent, Salisburylaan 133, B-9820 Merelbeke, België
${ }^{2}$ FAVV, Administratief Centrum Kruidtuin, Food Safety Center, Kruidtuinlaan 55, B-1000 Brussel, België
${ }^{3}$ Vakgroep Medische Beeldvorming en Orthopedie, Faculteit Diergeneeskunde, Universiteit Gent, Salisburylaan 133, B-9820 Merelbeke, België

vanloon.acj@gmail.com

\section{AMENVATTING}

Een vrouwelijke, gesteriliseerde labrador-retriever van zeven jaar oud werd aangeboden met klachten van tachypneu, kokhalzen en abdominale distensie. Op het lichamelijk onderzoek werden een systolische hartruis met een intensiteit van $3 / 6$ en punctum maximum links apicaal, tachycardie en zwak geslagen, femorale polsen opgemerkt. Een undulatieproef was positief. Na echocardiografisch en elektrocardiografisch onderzoek werden dilatorische cardiomyopathie (primair of secundair) en supraventriculaire tachycardie (SVT) vastgesteld. Na instelling van een behandeling met digoxine werd tijdens de opvolging een isoritmische atrioventriculaire dissociatie (IAVD) waargenomen en bleek de SVT onvoldoende onder controle gebracht. Na het overschakelen op diltiazem werd op het ECG vastgesteld dat de tachycardie onder controle was. Echocardiografisch onderzoek toonde aan dat het hart zich hersteld had. De hond vertoonde de daaropvolgende twee jaar geen cardiale symptomen meer. In deze casus wordt de zeldzame aritmie IAVD in combinatie met SVT beschreven. Daarnaast wordt het belang aangetoond van SVT als mogelijk reversibele oorzaak van een DCM-fenotype op echocardiografie.

\section{ABSTRACT}

A neutered, seven-year-old, female Labrador retriever was presented with complaints of tachypnea, gagging and abdominal distension. A left apical systolic murmur with an intensity of $3 / 6$, tachycardia, weak femoral pulses and positive undulation were observed on physical examination. After echocardiographic and electrocardiographic examination, dilated cardiomyopathy (primary or secundary) and supraventricular tachycardia were diagnosed. At a later control visit, after initiation of treatment with digoxin, electrocardiography revealed isorhythmic atrioventricular dissociation (IAVD) and poor control of the SVT. After transition to diltiazem, the tachycardia was well-controlled. A full recovery of the heart was observed on echocardiographic examination. Twenty-four months later, the dog showed no more cardiac signs. In this case report, a rare arrhythmia, i.e. IAVD in combination with SVT is described. It shows the importance of SVT as a reversible cause of a DCM-like phenotype on echocardiography.

\section{INLEIDING}

Een normale hartfrequentie bij de volwassen hond bevindt zich tussen de 70 en 160 slagen per minuut (bpm). Er wordt van tachycardie gesproken zodra de hartfrequentie deze bovengrens overstijgt. Tachycardie kan zowel een supraventriculaire of ventriculaire oorsprong hebben (Ware, 2013a). Tot de supraventriculaire tachyaritmieën (SVTs) behoren zowel de echte supraventriculaire ofwel atriale, alsook de 

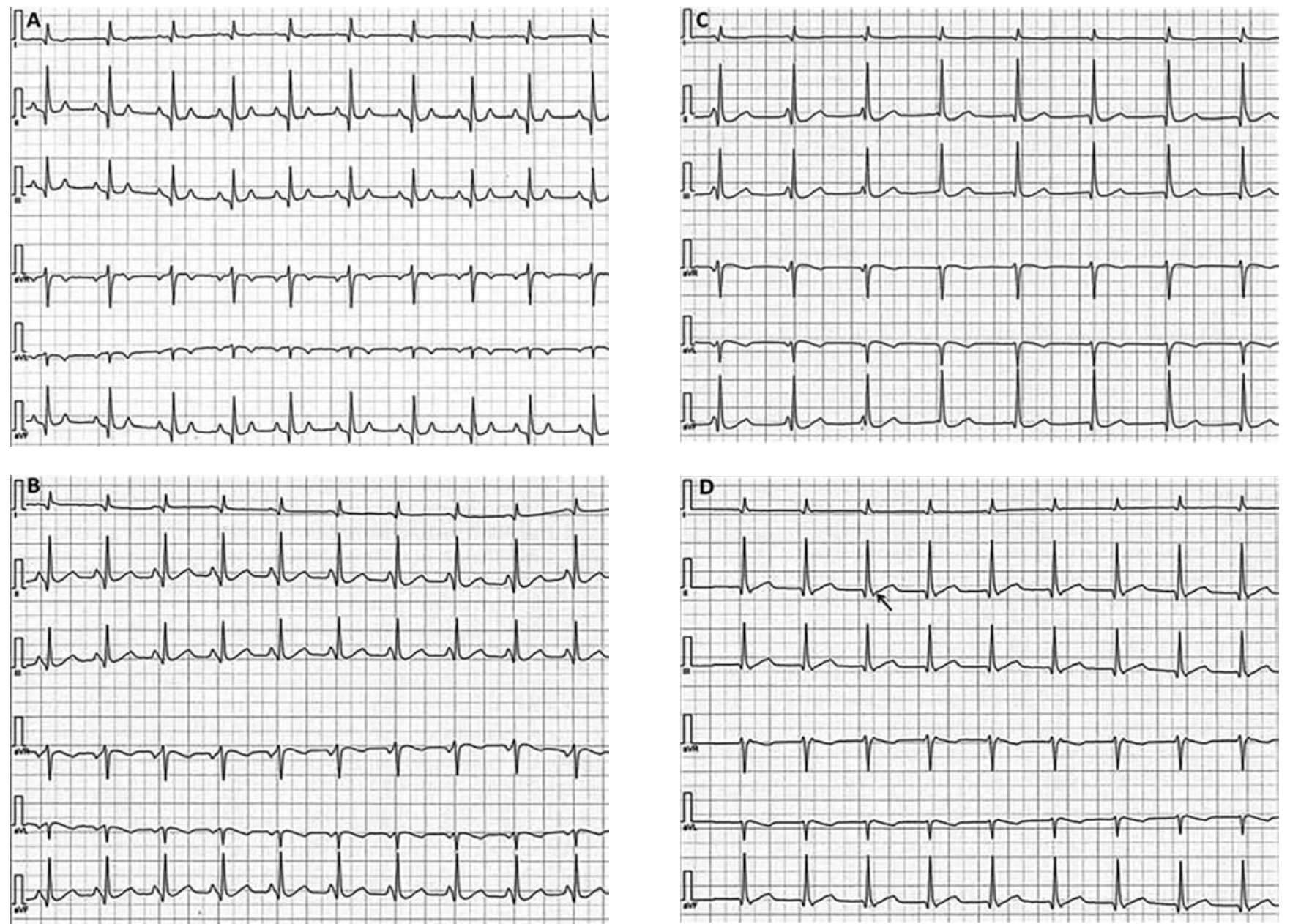

Figuur 1. Elektrocardiogram met afleidingen I, II, III, aVR, aVL en aVF van labrador-retrievers. A. Sinusritme. B. FJT met IAVD type II. C. FJT met IAVD type I. D. FJT met ventriculo-atriale conductie (uit: Perego et al., 2012).

junctionale of atrioventriculaire aritmieën. Dit zijn tachycardieën met een normale of supraventriculaire morfologie van de QRS-complexen op elektrocardiografie (ECG). De SVTs vinden hun oorsprong in de sinusknoop, het atriale myocard, de atrioventriculaire (AV) knoop en de bundel van His. De hartfrequentie van deze SVT bij de hond is vaak meer dan $180 \mathrm{bpm}$. Specifieke atriale SVTs zijn onder andere atriumfibrillatie (AF), atriale flutter (AFL) en focale atriale tachycardie (FAT). Onder de junctionale SVTs vallen orthodrome atrioventriculaire wederkerige ("reciprocating") tachycardie (OAVRT) en focale junctionale tachycardie (FJT) (Ware, 2013a; Pariaut et al., 2014).

IAVD is een fenomeen dat kan worden waargenomen op een oppervlakte-ECG in combinatie met een SVT (Perego et al., 2012). Hierbij hebben de atria en ventrikels ieder een eigen gebied waar de prikkel ontstaat. Deze gebieden depolariseren onafhankelijk van elkaar maar in een bijna gelijk ritme. De gangmaker van de atriale contractie is de sinusknoop, de gangmaker van de ventriculaire depolarisatie kan ofwel uit het junctionale gebied afkomstig zijn of een ventriculaire oorsprong hebben. De contractie van de atria en de ventrikels gebeurt daardoor nagenoeg in hetzelfde ritme maar wel onafhankelijk van elkaar. Daarbij zijn er twee types van IAVD: bij type I beweegt de P-golf heen en weer doorheen het QRS-complex, waardoor het PQ-interval verschilt (Figuur 1B). Bij type II is er een vaste relatie tussen de P-golf en het QRS-complex en is er dus een relatief vast PQ-interval (Figuur 1C). Hierbij kan de P-golf zich voor, in of net achter het QRS-complex bevinden. Ter vergelijking wordt in Figuur $1 \mathrm{~A}$ een sinusritme getoond. Bij een IAVD is er eveneens een diastolische dysfunctie, omdat het verdwijnen van de synchronisatie tussen de atria en de ventrikels resulteert in het verlies van de bijdrage van de atriale contractie in het eind-diastolisch volume van de ventrikel. Deze diastolische dysfunctie is het grootst wanneer de AV-kleppen gesloten zijn op het moment van de contractie van de atria (Perego et al., 2012).

De meest voorkomende SVT bij de hond is AF. AF ontstaat door de continue onafhankelijke activatie van multipele, ectopische gangmakers in het atriale myocard. Hierdoor verliest het atrium zijn gecoördineerde contractie. De AV-knoop geleidt de supraventriculaire prikkels at random met als resultaat een onregelmatig ritme met meestal een verhoogde frequentie ("ventricular response rate") van 130-260 bpm. AF kan alleenstaand voorkomen (eerder zelden bij de hond) 


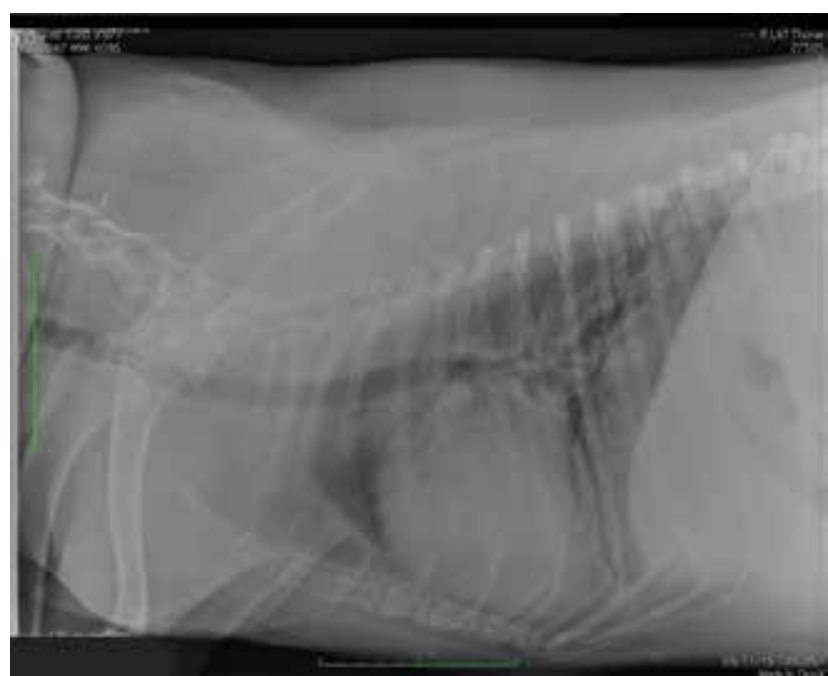

Figuur 2. Rechts laterale radiografische opname van de thorax op het moment van aanbieden. Vermoeden van een rechtszijdige cardiomegalie door vergroot contact met het sternum. Geen abnormaliteiten in de pulmonaire vascularisatie.

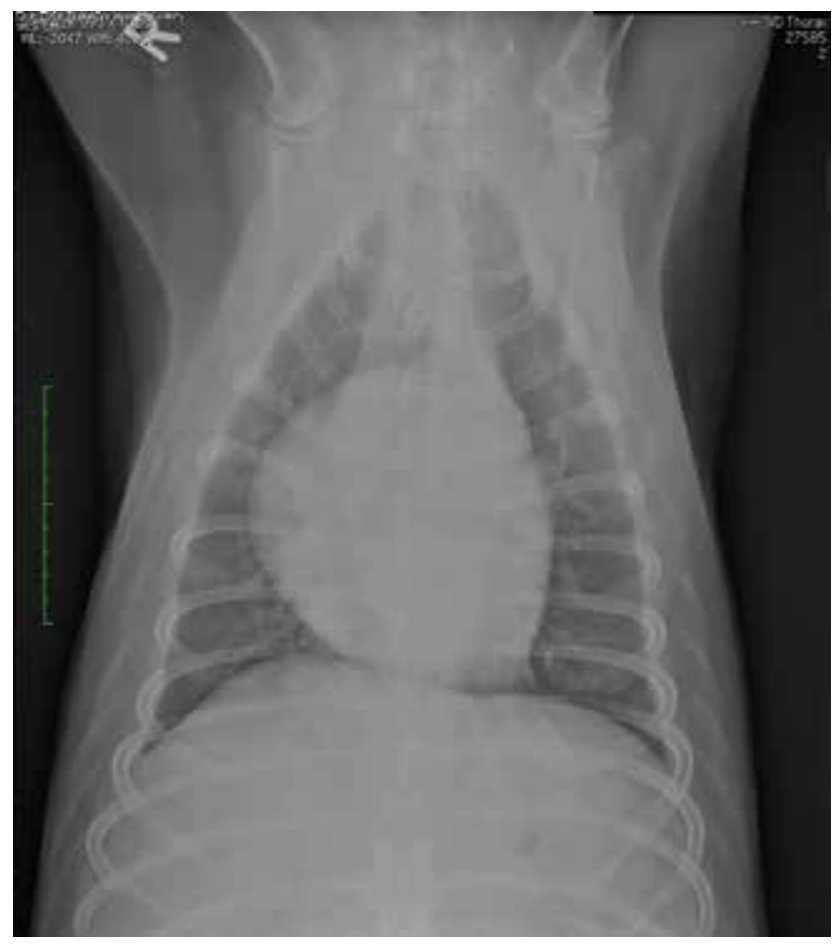

Figuur. 3. Ventrodorsale radiografische opname van de thorax op het moment van aanbieden. Vermoeden van een rechtszijdige cardiomegalie door de hartvorm als een omgekeerde $D$. Geen abnormaliteiten in de pulmonaire vascularisatie.

of meer frequent ten gevolge van een onderliggende, structurele hartaandoening (Menaut et al., 2005, Ware, 2013a; Pariaut et al., 2014). AFL is een atriale tachycardie met een hartfrequentie van meestal boven de $300 \mathrm{bpm}$ en met een regelmatig ritme (Pariaut et al., 2014). De prikkel komt uit een gangmaker in het atrium die zichzelf herhaaldelijk depolariseert, wat "re-entry" wordt genoemd. Bij AFL is er in tegenstelling tot AF nog een gecontroleerde contractie van het atriale myocard (Ware, 2013a; Pariaut et al., 2014). Bij atriale, premature complexen ontstaat de impuls vanuit een ectopische gangmaker in het atrium buiten de sinusknoop, waarbij de meerderheid van de FAT uit een ectopische gangmaker in het rechteratrium komt (Pariaut et al., 2014). De FAT is een tachycardie met een hartfrequentie rond de $210-230 \mathrm{bpm}$ en een meestal onregelmatig ritme. OAVRT zijn re-entrytachyartimieën, waarbij de prikkel meestal vanuit de junctionale regio via de normale geleidingsweefsels naar de ventrikels wordt geleid, maar waar er via een "accessory pathway" een ventriculoatriale geleiding terug naar de AV-knoop is, waardoor deze opnieuw depolariseert. De hartfrequentie ligt bij deze aritmie vaak tussen de 180-300 bpm met een regelmatig RR-interval (Santilli, 2000; Pariaut et al., 2014). Daarnaast wordt OARVT geassocieerd met een accessoire pathway beschreven bij de labrador-retriever (Wright et al., 1996; Santilli et al., 2006). FJT is een zeldzame hartritmestoornis die ontstaat door een snelle ontlading van de junctionale regio aan een regelmatig ritme van 120-200 bpm (Perego et al., 2012; Pariaut et al., 2014). FJT kan worden gekenmerkt door een 1:1 ventriculo-atriale conductie: de elektrische prikkel ontstaan in de junctionale regio wordt retrograad naar het atriale myocard geleid (Figuur 1D). Soms wordt deze 1:1 ventriculoatriale conductie afgewisseld met IAVD. IAVD werd beschreven bij elf labrador-retrievers waarbij een associatie met FJT werd verondersteld (Perego et al., 2012) .

Deze hogergenoemde SVT kunnen van elkaar gedifferentieerd worden aan de hand van hun karakteristieken op een oppervlakte-ECG (hartfrequentie, regelmaat, identificatie p'-golf, Rp'- interval, elektrische as van de p'-golf, QRS-complex alternans, abrupt of gradueel begin en einde) en hun respons op vagale maneuvers (Santilli et al., 2008; Pariaut et al., 2014). Voor een definitieve diagnose is echter elektrofysiologisch onderzoek noodzakelijk.

Een mogelijk gevolg van een SVT is een zogenaamde tachycardie-geïnduceerde cardiomyopathie (TICM). Dit is meestal een systolische dysfunctie van het myocard met als onderliggende oorzaak een al dan niet op dat moment aanwezige tachyaritmie (Umana et al., 2003; Khasnis et al., 2005; Ware, 2013b; Pariaut et al., 2014). Echocardiografisch vertoont het hart veranderingen die overeenkomen met het beeld dat wordt gezien bij dilatorische cardiomyopathie (DCM), zoals linkeratrium- en linkerventrikeldilatatie en systolische dysfunctie (Umana et al., 2003; Khasnis et al., 2005; Ware, 2013b). Zowel supraventriculaire als ventriculaire tachyaritmieën (VT) kunnen progressieve wijzigingen in het myocard teweegbrengen via verscheidene mechanismen, zoals energiedepletie in de mitochondriën, myocardiale ischemie en oxidatieve stress (Zupan et al., 1996). De wijzigingen in de myocyten, de extracellulaire matrix, de neurohumorale activatie en de elektrofysiologie leiden tot de morfologische en functionele veranderingen die met radiografie en echocardiografie worden waargenomen 
(Shinbane et al., 1997; Umana et al., 2003; Khasnis et al., 2005). De veranderingen van het hart en de daarmee gepaard gaande dysfunctie zijn voornamelijk afhankelijk van de duur van de tachycardie en de hartfrequentie. Hoe hoger de hartfrequentie, des te sneller er afwijkingen in het myocard ontstaan (Shinbane et al., 1997). Verder induceren continue tachycardieën meer schade dan intermitterende (Moe et al., 1995). Continue SVTs aan een hartfrequentie van $180 \mathrm{bpm}$ kunnen in drie weken al aanleiding geven tot ventriculaire dysfunctie (Zupan et al., 1996; Shinbane et al., 1997). In een studie van Riegger en Liebau (1981) traden ernstige ventriculaire dysfunctie en sterfte op ten gevolge van fatale aritmie en congestief hartfalen bij een frequentie van 240-280 bpm gedurende veertien dagen. Daarnaast toonden Zupan et al. (1996) aan dat chronische VT een groter effect heeft op beschadiging van het hart dan chronische SVT. Bovendien is de kans op plotse sterfte door de verandering naar een maligne aritmie groter bij VT (Khasnis et al., 2005; Oyama en Reynolds, 2014). Indien de oorzakelijke aritmie laattijdig wordt opgemerkt of de ingestelde therapie inadequaat is, kunnen de structurele veranderingen zodanig vergevorderd en irreversibel zijn, dat volledig herstel van de dysfuncties niet meer mogelijk is (Gopinthannair et al., 2015).

Op echocardiografisch onderzoek hebben TICM en primaire DCM een gelijkaardig uitzicht. Bij beide aandoeningen is er een dilatatie van één of meerdere hartkamers met systolische dysfunctie (Santilli, 2000; Ware, 2013b; Pariaut et al., 2014). Hierbij is de dilatatie van het linkerhart vaak het meest prominent, de ventrikels hebben een afgeronde vorm en de wanddikte kan normaal tot afgenomen zijn (Shinbane et al., 1997; Wess et al., 2010; Ware, 2013b; Gupta en Figueredo, 2014). Door annulaire dilatatie kan secundair mitralis- en tricuspidalisklepregurgitatie ontstaan (Shinbane et al., 1997; Khasnis et al., 2005; Gupta en Figueredo, 2014). Aldus moet bij een patiënt met de morfologische en functionele kenmerken van DCM en bij de aanwezigheid van een aritmie TICM in de differentiaaldiagnose worden opgenomen (Umana et al., 2003; Khasnis et al., 2005; Wright, 2015). De diagnose van TICM wordt vaak pas bevestigd na normalisatie van het hart door de ingestelde antiaritmische therapie (Umana et al., 2003; Gopinathannair et al., 2015).

Honden met TICM en de geassocieerde tachycardie zijn vaak asymptomatisch. In dat geval wordt de aandoening vaak per toeval ontdekt, bijvoorbeeld tijdens een lichamelijk routineonderzoek (Pariaut et al., 2014). Anderzijds worden sommige honden pas aangeboden met tekenen van linker en/of rechter congestief hartfalen. Symptomen van congestief hartfalen zijn onder andere tachypneu, dyspneu, hoesten, pleurale effusie, longoedeem en abdominale distensie (DeFrancesco, 2013). Soms worden eerdere tekenen, zoals inspanningsintolerantie, lethargie, een snelle hartslag en hijgen door de eigenaar opgemerkt (Pari- aut et al., 2014; Wright, 2015). Tekenen van gastrointestinale origine, zoals braken, kokhalzen en partiele anorexie, kunnen ook voorkomen (DeFrancesco, 2013; Wright, 2015).

De therapie voor TICM is tweeledig en bestaat uit een ondersteunende behandeling en een antiaritmische behandeling (Gopinathannair et al., 2015). Met de ondersteunende therapie wordt getracht de systolische functie te verbeteren en de progressie naar hartfalen tegen te gaan of in het geval van hartfalen deze te behandelen (Ware, 2013b). De antiaritmische behandeling is eveneens zeer belangrijk omdat het tijdig instellen van een adequate antiaritmische therapie een volledig herstel van het hart kan betekenen (Umana et al., 2003; Ware, 2013b; Pariaut et al., 2014; Gopinathannair et al., 2015).

In de onderstaande casus wordt een labrador-retriever met een combinatie van SVT en IAVD en een geassocieerde TICM beschreven.

\section{CASUISTIËK}

Een vrouwelijke, gesteriliseerde labrador-retriever van bijna zeven jaar oud werd aangeboden met klachten van kokhalzen sinds een maand. De hond kokhalsde enkele keren per dag zonder aanleiding of tekenen van misselijkheid. Braken was afwezig. Sinds één week waren ook klachten ontstaan van een snellere ademhaling met een licht snuivend geluid, toegenomen buikomvang en had de eigenaar een hoge hartfrequentie opgemerkt.

Op het algemeen lichamelijk onderzoek had de hond een body condition score van 6/9 en woog 33,6 $\mathrm{kg}$. Ze vertoonde tachypneu (64 per minuut) en produceerde mild versterkte ademhalingsgeluiden. Het dier vertoonde eveneens tachycardie (180 tot $240 \mathrm{bpm}$ ) en er was bilateraal een systolische hartruis met een intensiteit van $3 / 6$ hoorbaar met punctum maximum links apicaal. De femorale polsen waren zwak geslagen, wisselend gevuld en af en toe was een polsdeficit aanwezig. De hond vertoonde ook een matige abdominale distensie; een undulatieproef was positief.

Tijdens de eerste consultatie werd een radiografisch onderzoek van de thorax uitgevoerd om mogelijke oorzaken van de milde tachypneu op te sporen. Omwille van de hartruis en de tachycardie werden een echocardiografisch onderzoek en ECG uitgevoerd. Een volledig bloedonderzoek (hematologie, biochemie) werd uitgevoerd gezien de middelbare leeftijd van de hond en de elektrolyten werden bepaald omwille van de mogelijkheid van een aritmie.

Op de thoracale radiografieën werd op de rechts laterale opname een verhoogd contact tussen het hart en het sternum gezien en op de ventrodorsale opname had het hart de vorm van een omgekeerde D (Figuur 2 en 3), wijzend op een mogelijke, rechtszijdige cardiomegalie, met een "vertebral heart scale" van $11(8,5$ $10,9)$; een echocardiografisch onderzoek werd gead- 


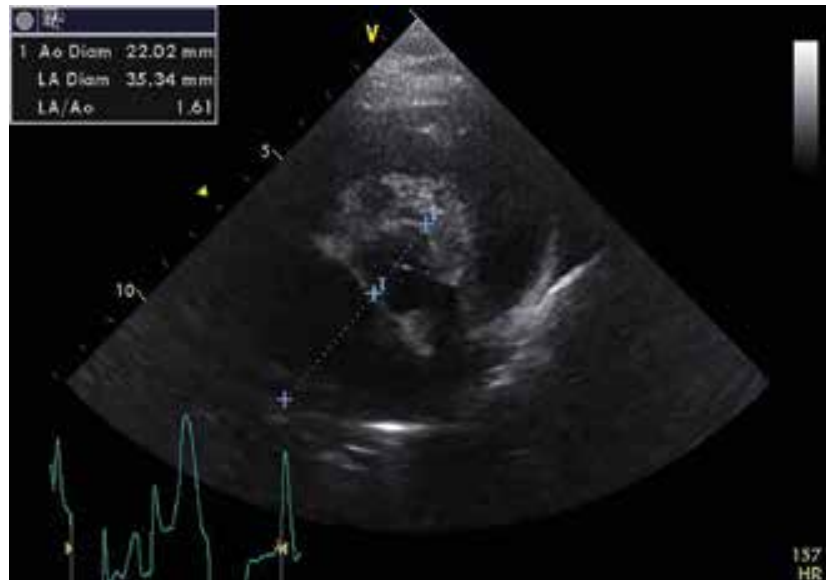

Figuur 4. Aanwezigheid van een milde linkeratriumdilatatie (dwarse doorsnede linkerhartbasis) tijdens het eerste echocardiografisch onderzoek.

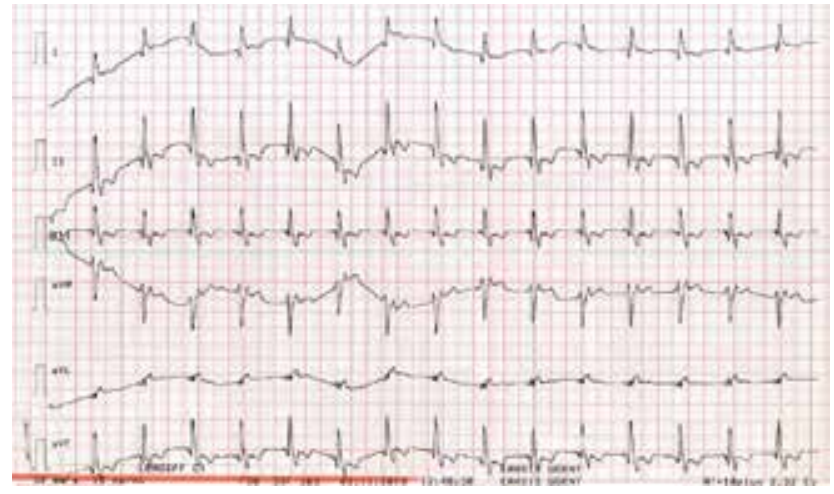

Figuur 6. Het ECG afgenomen tijdens de eerste consultatie toont een hartfrequentie van $210 \mathrm{bpm}$, normaal uitziende QRS-complexen en moeilijk te identificeren P-golven.

viseerd. Er werden geen afwijkingen in de pulmonaire vasculatuur opgemerkt die indicatief konden zijn voor congestie. De grootte van het linkeratrium was tevens normaal. De slokdarm vertoonde evenmin afwijkingen. Door deze radiografische bevindingen konden de tachypneu en het kokhalzen dus niet verklaard worden. De vena cava caudalis kon niet worden beoordeeld op deze opnames.

Het echocardiografisch onderzoek toonde een milde linkeratriumdilatatie aan met een LA/Ao ratio van 1,6 (normaal $<1,5$ ) (Figuur 4 en 5; Tabel 1). Het rechteratrium was tevens vergroot en de rechterventrikel prominent. De "fractional shorting" (FS) was matig (Gugjoo et al., 2014). De linkerventrikeldiameter in diastole viel boven het rasspecifieke referentieinterval voor de labrador-retriever en de systolische diameter was hoog normaal (Gugjoo et al., 2014). De volumes van het linkerventrikel gemeten met de Simpson-methode en wanddiktes gemeten met de Mmode vielen binnen het referentiebereik (Gerlach en Wess, 2009; Gugjoo et al., 2014). Er was een milde regurgitatie ter hoogte van de tricuspidalisklep en van de mitralisklep, wat de matige hartruis kon verklaren.

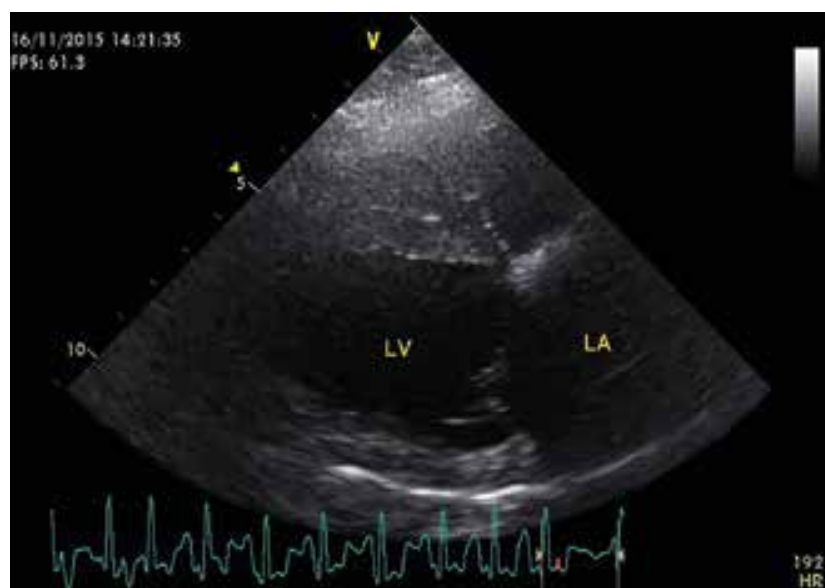

Figuur 5. Aanwezigheid van een milde linkeratriumdilatatie (overlangse doorsnede vier-kamerbeeld) tijdens het eerste echocardiografisch onderzoek.

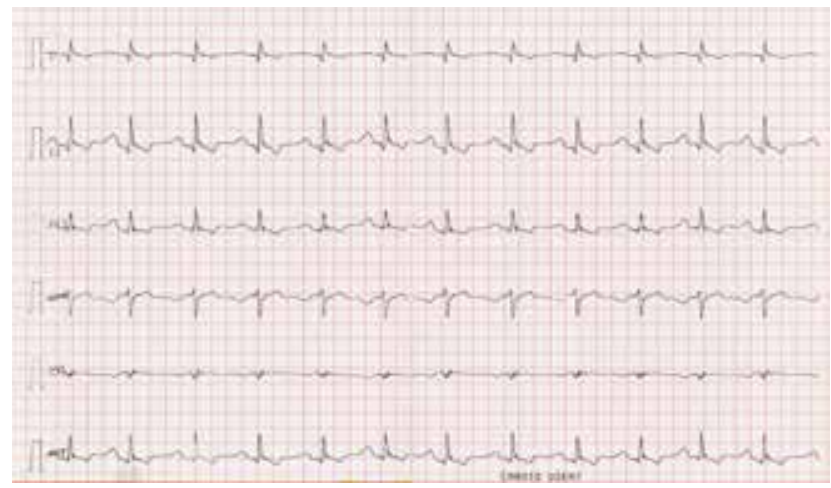

Figuur 7. ECG met een sinusritme met een eerstegraadAV-blok en een hartfrequentie van 140 bpm.

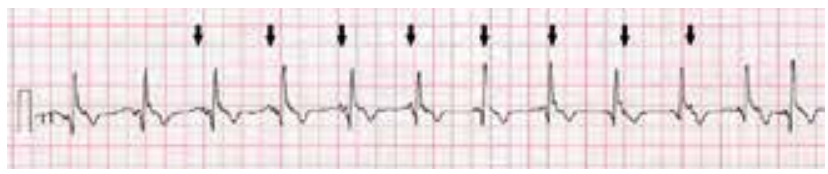

Figuur 8. ECG met een hartfrequentie van 170-180 bpm. Detail met FJT en IAVD met synchronisatie type I; de P-golf beweegt heen en weer in het QRS-complex (pijlen). Dit ECG is afgenomen 13 weken na initiële presentatie. De hond werd in die periode behandeld met digoxine $0,22 \mathrm{mg} / \mathrm{m}^{2}$ q12u en sotalol $0,6 \mathrm{mg} / \mathrm{kg} \mathrm{q12u}$.

De ejectiefractie op basis van de LV-volumes bedroeg $32 \%$, de "E-point-septal separation" (EPSS) bedroeg 7,8 en de sfericiteitsindex 1,09 . Als differentiaaldiagnosen voor deze bevindingen komen in aanmerking: beginnende primaire dilatorische cardiomyopathie, secundaire dilatorische cardiomyopathie, beide met secundaire mitralisklepinsufficiëntie of mitralisklepdegeneratie in een vroege "stage B2" volgens de ACVIM-classificatie. Na het echocardiografisch onderzoek werd het abdomen eveneens kortstondig gescand. De lever en levervenen leken subjectief vergroot en er was een zeer milde hoeveelheid abdominale effusie aanwezig. 
Het ECG toonde tachycardie met een hartfrequentie van 210 bpm (Figuur 6). De QRS-complexen hadden een supraventriculair uitzicht en er was geen duidelijk zichtbare P-golf waar te nemen, waardoor initieel werd gedacht aan AF. Het ritme was hiervoor echter te regelmatig en bovendien was er bij nadere inspectie een vermoeden van P-golven in afleiding II en aVL.

Het bloedonderzoek inclusief ionogram gaf geen significante afwijkingen weer. Omwille van de mogelijkheid van myocarditis werd het cardiaal troponine-I bepaald, die zeer mild verhoogd was met een waarde van $0,11 \mathrm{ng} / \mathrm{ml}(>0,08 \mathrm{ng} / \mathrm{ml})$.

Naar aanleiding van het initiële vermoeden van primaire of secundaire cardiomyopathie of beginnende mitralisklependocardiose met AF werd voor de SVT een behandeling opgestart met digoxine (Lanoxin, Aspen Pharma, Ierland; $0,22 \mathrm{mg} / \mathrm{m}^{2} \mathrm{q} 12 \mathrm{u}$ ) en omwille van de milde cardiomegalie en de systolische dysfunctie werd pimobendan (Vetmedin, Boehringer Ingelheim, Duitsland; $0,25 \mathrm{mg} / \mathrm{kg} \mathrm{q} 12 \mathrm{u}$ ) toegediend. Een lage dosis furosemide (Furosemide EG, Eurogenerics, België; $1,2 \mathrm{mg} / \mathrm{kg} \mathrm{q} 12 \mathrm{u}$ ), benazepril en spironolactone (Cardalis, Ceva, België; $0,3 \mathrm{mg} / \mathrm{kg}$ en 2,5 $\mathrm{mg} / \mathrm{kg} \mathrm{q} 24 \mathrm{u}$ ) werden toegevoegd omwille van mogelijk beginnend rechter congestief hartfalen, alhoewel deze diagnose op dat moment niet vaststond en eerder preventief werd opgestart. Eén week na het opstarten van de digoxinebehandeling werd de digoxinespiegel gecontroleerd aangaande de nauwe toxisch-therapeutische marge. Deze spiegel werd normaal bevonden en er werd atenolol (Atenolol EG, Eurogenerics, België) toegevoegd. Deze werd geleidelijk opgebouwd tot een dosis van $0,4 \mathrm{mg} / \mathrm{kg} \mathrm{q} 12 \mathrm{u}$ om de hartfrequentie beter onder controle te krijgen omdat de tachycardie (170-240 bpm) tijdens de digoxinemonotherapie nog altijd aanwezig was.

$\mathrm{Na}$ telefonisch overleg met de eigenaar werd de toediening van atenolol stopgezet omdat de hond er neveneffecten van ondervond, waaronder zwakte en lethargie. Na het stopzetten verdwenen deze klachten en werd een lage dosis sotalol (Sotalol Sandoz, Sandoz, België; 0,6 mg/kg q12u) opgestart ter vervanging van atenolol. De hartslag was zowel thuis als tijdens auscultatie en bij het ECG op consultatie rond de 150 $\mathrm{bpm}$. Een echocardiografische controle gaf een normale grootte van het linkeratrium aan als ook linkerventrikeldiameters die binnen de referentiewaarden vielen (Tabel 1). De FS bedroeg 36\% en was dus genormaliseerd (Gugjoo et al., 2014). De regurgitatie ter hoogte van de mitralisklep was onveranderd. Daar er verbeteringen werden waargenomen ten opzichte van de vorige echocardiografie werd de toediening van furosemide en pimobendan geleidelijk afgebouwd.

Dertien weken na initiële presentatie werden zowel een echocardiografische als ECG-controle en een nieuw bloedonderzoek uitgevoerd. Na de laatste consultatie werden geen klachten opgemerkt en maakte de hond het goed. De medicatie was digoxine $0,22 \mathrm{mg} /$ $\mathrm{m}^{2} \mathrm{q} 12 \mathrm{u}$ en sotalol $0,6 \mathrm{mg} / \mathrm{kg} \mathrm{q} 12 \mathrm{u}$. Bij het lichamelijk onderzoek waren er geen afwijkingen, behalve de gekende hartruis. De hartfrequentie bedroeg initieel ongeveer $130 \mathrm{bpm}$. Op het hematologisch, biochemisch en ionografisch onderzoek waren er geen afwijkingen aanwezig. Op het echocardiografisch onderzoek vielen alle parameters binnen de normaalwaarden; de grootte van het linkeratrium was echter wat toegenomen (Tabel 1). De mitralisklepinsufficiëntie werd als mild tot matig beoordeeld met een normale drukgradiënt. De tricuspidalisklepinsufficiëntie was onveranderd. Tijdens dit controlebezoek werden meerdere ECGs afgenomen, waarbij in het eerste ECG een sinusritme (SR) met een eerstegraad-AV-blok en een hartfrequentie van $140 \mathrm{bpm}$ aanwezig waren (Figuur 7). Bij de daaropvolgende ECGs was er een SVT (met een gemiddelde frequentie van 172-188 bpm) aanwezig met IAVD type I (Figuur 8). Het feit dat er op dat moment intermitterend een sinusritme aanwezig was,

Tabel 1. Evolutie van enkele echocardiografische parameters.

\begin{tabular}{|c|c|c|c|c|c|}
\hline Echocardiografisch onderzoek & $\begin{array}{c}1 \\
(\mathrm{T0})\end{array}$ & $\begin{array}{c}2 \\
(4 w)\end{array}$ & $\begin{array}{c}3 \\
(13 w)\end{array}$ & $\begin{array}{c}4 \\
(52 w)\end{array}$ & Ref. \\
\hline Grootte linkeratrium (mm) ${ }^{1}$ & 37,2 & 28,7 & 30,7 & 30,5 & $19,3-25,1$ \\
\hline LA/Ao ratio & 1,6 & 1,3 & 1,5 & 1,5 & $<1,5$ \\
\hline Linkerventrikel diastolische diameter $(\mathrm{mm})^{1}$ & 49,2 & 44,2 & 45,1 & 43,1 & $29,4-45,3$ \\
\hline Linkerventrikel systolische diameter $(\mathrm{mm})^{1}$ & 35,3 & 28,1 & 33,1 & 29,0 & $14,5-36,8$ \\
\hline $\begin{array}{l}\text { Linkerventrikelvolume in diastole } \\
\quad(\text { Simpson's method of discs })\left(\mathrm{mL} / \mathrm{m}^{2}\right)^{2}\end{array}$ & 43,8 & 50,5 & 57,4 & 54,8 & $<100$ \\
\hline $\begin{array}{l}\text { Linkerventrikelvolume in systole } \\
\quad\left(\text { Simpson's method of discs) }\left(\mathrm{mL} / \mathrm{m}^{2}\right)^{2}\right.\end{array}$ & 30,6 & 28,6 & 32,0 & 29,0 & $<53$ \\
\hline FS $(\%)^{1}$ & 22,6 & 36,4 & 26,5 & 33 & $18,8-49,7$ \\
\hline
\end{tabular}

${ }^{1}$ Uit: Gugjoo et al., 2014.

${ }^{2} \mathrm{Naar}$ : Gerlach en Wess, niet-publiceerde data (2009). Referentiewaarden gebaseerd op een studie bij 300 gezonde honden van verschillende rassen, gezien er geen rasspecifieke referentiewaarden bestaan voor de labrador-retriever.

T0: tijdstip van aanbieden; 4w,13w, 52w: aantal weken na initiële presentatie; Ref.: referentiewaarden 


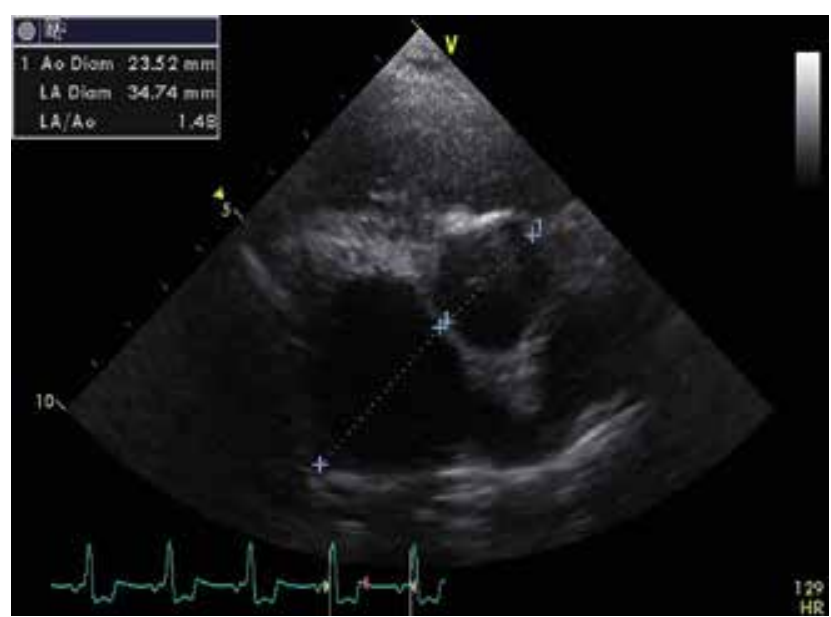

Figuur 9. Echocardiografisch controleonderzoek met normalisatie van de linkeratriumgrootte (dwarse doorsnede linkerhartbasis) 52 weken na initiële presentatie.

afwisselend met een supraventriculaire tachycardie en IAVD, leidde tot een vergelijking met het eerste ECG. Er werd vastgesteld dat de initiële diagnose van $\mathrm{AF}$ niet correct was, gezien de RR-intervallen te regelmatig waren. Mogelijke differentiaaldiagnosen die voor het initiële ECG toen in acht werden genomen, waren OAVRT geassocieerd met een "accessory pathway", FJT en FAT. De meest waarschijnlijke oorzaken van de IAVD en SVT bij deze controle waren FJT met IAVD, beschreven bij de labrador-retriever of digoxinetoxiciteit, wat IAVD met een junctionaal ritme kan veroorzaken (Bonagura en Muir, 1992; Perego et al., 2012). Omdat de hartfrequentie intermitterend nog zeer hoog was en omwille van de mogelijkheid van digoxinetoxiciteit werd besloten om de antiaritmische therapie te wijzigen. De toediening van digoxine en sotalol werd afgebouwd en uiteindelijk gestopt. De hond werd gehospitaliseerd om de hartfrequentie te monitoren. Er werd overgeschakeld op diltiazem (Progor, SMB, België; 4,2mg/kg q12u) en pimobendan $(0,25 \mathrm{mg} / \mathrm{kg} \mathrm{q} 12 \mathrm{u})$. Na de overschakeling op diltiazem werd op het ECG een SR met een hartfrequentie van 140-160 bpm waargenomen en de hond werd na drie dagen ontslagen.

Anderhalve week na de hospitalisatie werd een holter-monitoring uitgevoerd. In totaal werd er 23 uur gemonitord, waarbij de hoogst gemeten hartfrequentie $273 \mathrm{bpm}$ was tijdens het eten en de laagste hartfrequentie $54 \mathrm{bpm}$ tijdens de slaap. De gemiddelde hartfrequentie was $130 \mathrm{bpm}$ in een sinusritme, hoewel er periodes aanwezig waren met supraventriculaire tachycardie, vermoedelijk FJT, met fasen van AV-dissociatie. Er werden geen significante pauzes, bradycardieën of ventriculaire ritmestoornissen waargenomen. Het resultaat van deze holter-monitoring bevestigde dat de tachycardie met de huidige medicatie over het algemeen goed onder controle was.

Sindsdien bleef de hond symptoomloos op alle volgende controleonderzoeken. De hartfrequentie werd thuis door de eigenaar regelmatig opgevolgd en

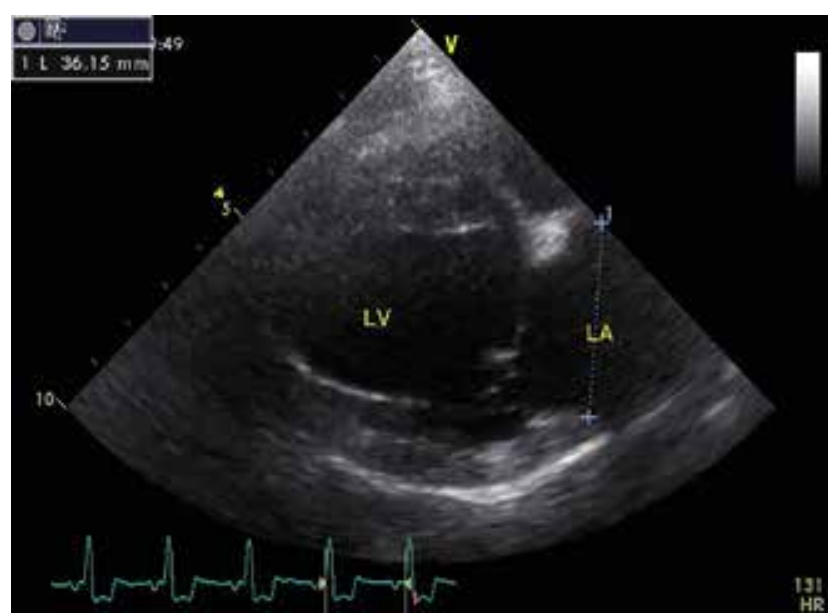

Figuur 10. Echocardiografisch controleonderzoek met normalisatie van de linkeratriumgrootte (overlangse doorsnede vier-kamerbeeld) 52 weken na initiële presentatie.

bleef stabiel rond $120 \mathrm{bpm}$. Ook op het lichamelijk onderzoek was de hartfrequentie rond $120 \mathrm{bpm}$ en waren er geen afwijkingen aanwezig buiten de reeds gekende hartruis. Op het echografisch controleonderzoek waren de afmetingen stabiel gebleven (Figuur 9 en 10; Tabel 1). De grootte van het linkeratrium was op de grens van normaal. De mitralisklep was nodulair verdikt, maar de bijbehorende regurgitatie was stabiel gebleven ten opzichte van de vorige keren en werd als een myxomateuze mitralisklepdegeneratie ACVIM stage B1 gestageerd. Zolang de hond geen klachten vertoonde, werden er drie- tot zesmaandelijkse controleonderzoeken ingepland. De ECGs bij opvolging toonden dat de hartfrequentie onder controle was (gemiddeld 120-140 bpm), al was dit niet altijd een sinusritme, zoals weergegeven op het ECG in Figuur 11, waar negatieve p-golven waar te nemen zijn. Cardiologisch bleef de hond stabiel, maar 16 maanden na de eerste presentatie werd ze aangeboden

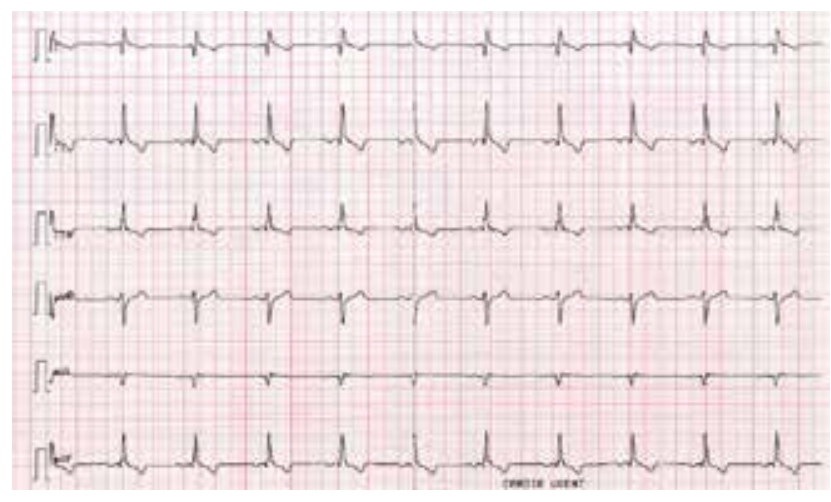

Figuur 11. ECG-controle tijdens de behandeling met diltiazem en pimobendan 52 weken na initiële presentatie. De hartfrequentie schommelt rond $120 \mathrm{bpm}$ in een regelmatig ritme. Elk QRS-complex wordt voorafgegaan door een $P$-golf waarmee ze in relatie staat. De P-golf is negatief in afleiding II, III en aVF en dus niet afkomstig uit de sinusknoop. 
op de dienst Endocrinologie van de Faculteit Diergeneeskunde (UGent) met klachten van polydipsie, vermageren en een slechte vachtkwaliteit. Daar werd een diagnose van hypercortisolisme gesteld, vermoedelijk ten gevolge van een bilaterale bijnierneoplasie. Trilostane (Vetoryl, Dechra, Verenigd Koninkrijk; 1,2 $\mathrm{mg} / \mathrm{kg} \mathrm{q} 12 \mathrm{u}$ ) werd opgestart waarna de symptomen verbeterden. Vierendertig maanden na initiële presentatie was de hond cardiologisch stabiel.

\section{DISCUSSIE}

In deze casus wordt een SVT met IAVD bij een vrouwelijke labrador-retriever van middelbare leeftijd beschreven met TICM als gevolg. De hond werd aangeboden omwille van klachten van tachypneu, abdominale distensie en kokhalzen. Op lichamelijk onderzoek werden tachypneu, tachycardie, een systolische hartruis met punctum maximum links apicaal en een intensiteit van 3/6, zwak geslagen polsen en een zeer milde hoeveelheid abdominale effusie vastgesteld. Omdat aan een cardiologisch probleem werd gedacht, werden een radiografie van de thorax en een echocardiografie uitgevoerd, waarbij een milde linkeratriumen ventrikeldilatatie, een rechteratriumdilatatie en een milde systolische dysfunctie werden vastgesteld. Differentiaal diagnostisch kwamen hiervoor een beginnende primaire DCM, een tachycardie-geïnduceerde DCM of een beginnende mitralisendocardiose ACVIM stage B2 in aanmerking.

Voor het kokhalzen werd er geen verklaring gevonden. Het was ook onduidelijk of er wel degelijk sprake was van kokhalzen, vermits de auteurs zich enkel konden baseren op de beschrijving van de eigenaar. Mogelijke oorzaken van kokhalzen zijn sinusproblemen, morfologische of functionele problemen van de farynx, aandoeningen van de bovenste of onderste luchtwegen of van de slokdarm (Kook, 2017). Een groot deel van de luchtwegen en de slokdarm was zichtbaar op radiografie; er werden geen abnormaliteiten opgemerkt. Omdat er geen problemen aanwezig waren met eten of drinken en omdat de focus bij het aanbieden lag op de aanwezigheid van een uitgesproken tachycardie en het vermoeden van een cardiaal probleem, werd deze klacht niet verder opgevolgd. De klacht van kokhalzen verdween volgens de eigenaar na het instellen van de antiaritmische therapie.

Grote en reuzenrassen zijn gepredisponeerd voor het ontwikkelen van primaire idiopathische DCM die vaak tot uiting komt rond de middelbare leeftijd, waardoor het onderscheid tussen primaire DCM en TICM moeilijk wordt (Foster et al., 2006). In deze casus waren de echocardiografische veranderingen echter vrij subtiel voor een primaire DCM; derhalve moesten secundaire oorzaken voor een echocardiografisch DCMbeeld dan ook in acht worden genomen. Mogelijke oorzaken van secundaire DCM zijn myocarditis, nutritionele deficiënties van taurine of L-carnitine, endocriene ziekten, zoals hypothyroïdie, tachycardieën en intoxicaties (Philips en Harkin, 2003; Sanderson, 2006; Ware, 2013b; Janus et al., 2014; Ware, 2014; Gallay-Lepoutre et al., 2016). Het bloedonderzoek gaf hematologisch, biochemisch en in het ionogram geen afwijkingen weer. T4 werd niet bepaald. De mild verhoogde serumcardiaaltroponine-I-concentratie was niet meteen indicatief voor acute myocarditis, een andere mogelijke oorzaak van cardiomyopathie.

Om de aanwezige tachycardie verder te onderzoeken werd een ECG afgenomen. Bij het eerste ECG, dat SVT aantoonde, werd door de zeer onduidelijke P-golven in afleiding II aanvankelijk gedacht aan AF. $\mathrm{AF}$ is een van de meest voorkomende SVTs bij middelgrote tot grote honden in combinatie met DCM (Ware, 2013b). Deze aritmie wordt bij de hond gekenmerkt door QRS-complexen met een supraventriculaire morfologie, de afwezigheid van P-golven, de mogelijke aanwezigheid van fibrillatiegolven, een onregelmatig $\mathrm{R}-\mathrm{R}$ interval en een gemiddelde frequentie van 130-230 bpm. Daardoor stond AF vooraan in de differentiaaldiagnose. Het R-R-interval was echter te regelmatig; bovendien waren er mogelijk p-golven te herkennen, wat atriumfibrillatie zeer onwaarschijnlijk maakte (Ware, 2013a; Pariaut et al., 2014) (Figuur 6). Andere SVTs met een regelmatig ritme zijn AFL met regelmatige geleiding (dus zonder variabele block), OAVRT geassocieerd met een "accessory pathway", FJT en soms FAT. Methoden om op een oppervlakte-ECG een onderscheid te maken tussen deze verschillende soorten SVTs zijn het vergelijken van hartfrequentie en regelmaat, de identificatie van atriale activatie (p'-golven, f-golven, F-golven) en het bepalen van de relatie tussen p'-golf en R-golf. $\mathrm{Er}$ waren meerdere differentiaaldiagnosen mogelijk voor het eerste ECG: als de p'-golf in het ST-segment verborgen zat, dan ging het om een korte R-P'-intervaltachycardie en waren FAT en OAVRT de meest waarschijnlijke differentiaaldiagnosen. Als ervan uit werd gegaan dat de p'-golf in AVR een positieve deflectie leek te hebben, dan was OAVRT de meest waarschijnlijke differentiaaldiagnose. Dit paste ook het beste bij de waargenomen hartfrequentie, gezien FAT (278 \pm $62 / \mathrm{min})$ meestal sneller is dan OAVRT $(229 \pm 42)$ (Santilli et al., 2008). Zoals bij OAVRT is er bij FJT ook retrograde concentrische activatie van het atrium en zijn er zogenaamde pseudo-S-golven aanwezig, die ook herkenbaar zouden kunnen geweest zijn op het initiële ECG (Perego et al., 2012). Op basis van dit eerste oppervlakte-ECG leken OAVRT, FJT en FAT de meest waarschijnlijke differentiaaldiagnosen.

Bij een van de volgende ECG-controles werd echter IAVD opgemerkt. IAVD werd eerder al beschreven in combinatie met FJT specifiek bij labrador-retrievers (Perego et al., 2012). Echter, op het moment dat in de voorliggende casus IAVD werd vastgesteld, kreeg de hond digoxine en sotalol toegediend. IAVD met een versneld junctionaal ritme werd reeds eerder gedocumenteerd bij digoxinetoxiciteit (Bonagura en Muir, 1992). Na het instellen van de therapie met diltiazem werden negatieve p-golven vastgesteld in afleiding II, 
III en aVF voorafgaand aan de QRS-complexen (gemiddelde HF 120/min) (Figuur 11). Normaal gezien zijn p-golven positief als de prikkelgeleiding uit de sinusknoop komt. Gezien negatieve p-golven geen sinus p-golven zijn, kunnen zij beschouwd worden als p'-golven. Deze komen vóór het QRS-complex voor, met in dit geval een lang RP'-interval. SVT die deze ECG-karakteristieken kunnen verklaren zijn FAT vanuit een laag gelegen regio uit het rechteratrium, waarbij de ventriculaire "response rate" bij de hond van de huidige casus toen vertraagd werd door de behandeling met diltiazem, of een andere lange RP'tachycardie, zoals permanente junctionale reciproke tachycardie (PJRT) of OAVRT met verlengde ventriculo-atriale conductietijd (Santilli et al., 2008, 2013).

Deze casus illustreert de moeilijkheid om SVTs te differentiëren en te diagnosticeren aan de hand van een oppervlakte-ECG en toont aan dat er nood is aan meer centra waar elektrofysiologisch onderzoek van het hart kan uitgevoerd worden bij de hond. Zonder elektrofysiologisch onderzoek met een intracardiaal gemeten ECG blijven er meestal meerdere differentiaaldiagnosen bestaan voor complexere SVTs en is een definitieve diagnose vaak onmogelijk (Perego et al., 2012).

Voor de behandeling van de vermoedelijke AF werd initieel digoxine opgestart om de hartfrequentie te verlagen; dit is een zogenaamde "rate control"-strategie (Gelzer et al., 2009; Pariaut et al., 2014). Gezien de hartfrequentie middels deze enkelvoudige therapie onvoldoende onder controle was, werd een bijkomende behandeling met atenolol opgestart (Wright, 2015). De hond ondervond echter nevenwerkingen van deze $\beta$-blokker, waardoor op een lage dosis sotalol werd overgeschakeld. Sotalol is een Vaughn-Williamsklasse III anti-aritmicum en komt voor in een racemisch mengsel van $\mathrm{D}$ en $\mathrm{L}$-sotalol waarvan de $\mathrm{L}$-isomeer ook een $\beta$-blockade-effect heeft (Kato et al., 1986). Sotalol wordt meestal niet gebruikt als monotherapie bij een "rate control"-strategie voor atriumfibrillatie, maar werd hier gekozen ter vervanging van atenolol in combinatie met digoxine. Bij ECG-controle na de behandeling met digoxine en sotalol werd aangetoond dat de hartfrequentie nog steeds onvoldoende onder controle was op het moment dat IAVD werd gediagnosticeerd. Digoxinetoxiciteit is bovendien een mogelijke oorzaak van IAVD met een junctionale tachycardie (Bonagura en Muir, 1992). Antiaritmica die momenteel worden angeraden voor FJT voor conversie naar en behoud van sinusritme bij de hond zijn atenolol en diltiazem (Pariaut et al., 2014). Zowel atenolol en diltiazem heeft een negatief chronotroop effect door een vertraagde AV-nodale conductie, respectievelijk door een $\beta_{1}$-blokkade en een blokkade van de calciumkanalen. Gezien de neveneffecten die de hond in de huidige casus ondervond van atenolol, was diltiazem de enige overblijvende keuze voor medicamenteuze behandeling. Door het tijdig instellen van een adequate antiaritmische behandeling kan een
TICM volledig reversibel zijn. Verbetering van de systolische functie wordt het vroegst één week na het instellen van een therapie gezien. De volledige normalisering van de systolische functie wordt meestal na vier tot zes weken therapie bekomen (Khasnis et al., 2005; Gopinathannair et al., 2015). Als er door de remodelering van het hart echter geen volledig herstel mogelijk is, blijft een ondersteunende medicamenteuze behandeling nodig om de hartfunctie te ondersteunen en hartfalen uit te stellen (Santilli et al., 2014; Gopinathannair et al., 2015).

Naast controle van de hartfrequentie werd in deze casus een behandeling met pimobendan opgestart om eventuele progressieve systolische dysfunctie gelinkt aan de IAVD te voorkomen. IAVD is immers een nietfysiologisch verschijnsel, waarbij de atria contraheren tegen gesloten AV-kleppen, wat op lange termijn mogelijk schadelijk kan zijn (Perego et al., 2012). Dankzij het goed onder controle houden van de hartfrequentie middels de medicamenteuze toediening van diltiazem en pimobendan toonde de hond van deze casus geen klachten meer en waren de echocardiografische afmetingen genormaliseerd, wat illustreert dat de hond initieel hoogstwaarschijnlijk TICM heeft gehad. Het effect van diltiazem en het effect van pimobendan op herstel van het hart van de hond in huidige casus waren helaas niet van elkaar te onderscheiden. Wanneer de hond initieel een primaire DCM zou gehad hebben, kon er toen (34 maanden na de eerste presentatie) echocardiografisch echter een verslechtering verwacht worden, zelfs wanneer behandeld zou zijn geweest met pimobendan. Hierdoor werd TICM in deze casus meer waarschijnlijk. Er bleef echter een milde mitralis- en tricuspidalisklepsinsufficiëntie aanwezig en de hond ontwikkelde ook een milde verdikking van de mitralisklep, passend bij ouderdomgerelateerde myxomateuze klepdegeneratie. Sinds het instellen van de laatste therapie werd de hond drie- tot zesmaandelijks opgevolgd en was ze tot op het moment van schrijven cardiologisch stabiel.

\section{CONCLUSIE}

In deze casus wordt een zeldzame hartritmestoornis, i.e. IAVD geassocieerd met supraventriculaire tachycardie bij een labrador-retriever beschreven. Uit de casus kan besloten worden dat ondanks het uitzicht van DCM op echografie en een aanwezige aritmie niet direct geconcludeerd mag worden dat er sprake is van primaire idiopathische DCM. Omdat DCM en TICM echocardiografisch niet van elkaar onderscheiden kunnen worden, kan het onderscheid soms pas gemaakt worden tijdens een adequate behandeling van de onderliggende aritmie. Het tijdig stellen van de juiste diagnose is bij TICM echter van doorslaggevend belang omdat een (partiële) normalisatie van het hart kan worden bekomen mits de juiste antiaritmische behandeling. 


\section{LITERATUUR}

Bonagura J.D., Muir W.W. (1992). Anti-arrhytmic treatment. In: Tilly L.P. (editor). Essentials of Canine and Feline Electrocardiography. Third edition, Lea and Febiger, Londen, 320-364.

DeFrancesco T.C. (2013). Management of cardiac emergencies in small animals. Veterinary Clinics of North America: Small Animal Practice 43 (4), 817-842.

Gallay-Lepoutre J., Bélanger M.C., Nadeau M.E. (2016). Prospective evaluation of doppler echocardiography, tissue doppler imaging and biomarkers measurement for the detection of doxorubicin-induced cardiotoxicity in dogs: a pilot study. Research in Veterinary Science 105, 153-159.

Gelzer A.R., Kraus M.S., Rishniw M., Moïse N.S., Pariaut R., Jesty S.A., Hemsley S.A. (2009). Combinatino therapy with digoxin and diltiazem controls ventricular rate in chronic atrial fibrillation in dogs better than digoxin or diltiazem monotherapy: a randomized crossover study in 18 dogs. Journal of Veterinary Internal Medicine 23 (3), 499-508.

Gopinathannair R., Etheridge S.P., Marhlinski F.E., Spinale F.G., Lakkireddy D., Olshansky B. (2015). Arrhythmiainduced cardiomyopathies: mechanisms, recognition and management. Journal of the American College of Cardiology 66 (15), 1714-1728.

Gupta S., Figueredo V.M. (2014). Tachycardia mediated cardiomyopathy: pathophysiology, mechanisms, clinical features and management. International Journal of Cardiology 172 (1), 40-46.

Kook P.H. (2017). Gagging. In: Ettinger S.J., Feldman E.C., Côté E. (editors). Textbook of Veterinary Internal Medicine. Eighth edition, Elsevier Mosby, St. Louis, 152-154.

Foster S.F., Hunt G.B., Thomas S.P., Ross D.L., Pearson M.R.B., Malik R. (2006). Tachycardia-induced cardiomyopathy in a young Boxer dog with supraventricular tachycardia due to an accesory pathway. Australian Veterinary Journal 84 (9), 326-331.

Gerlach P.A., Wess G. (2009). Unpublished data.

Janus I., Noszczyk-Nowak A., Nowaak M., Cepiel A., Ciaputa R., Paslawska U., Dziegiel P., Jablonska K. (2014). Myocarditis in dogs: etiology, clinical and histopathological features (11 cases: 2007-2013). Irish Veterinary Journal 67 (1), 1-8.

Kato R., Ikeda N., Yabek S.M., Kannan R., Singh B.N. (1986). Elektrophysiological effects of the levo ad dextrorotatory isomers of sotalol in isolated cardiac muscle and their in vivo pharmakinetics. Journal of the American College of Cardiology 7 (1), 116-125.

Khasnis A., Jongnarangsin K., Abela G., Veerareddy S., Reddy V., Thakur R. (2005). Tachycardia-induced cardiomyopathy: a review of literature. Pacing and Clinical Electrophysiology 28 (7), 710-721.

Menaut P., Bélanger M.C., Beauchamp G., Ponzio N.M., Moïse N.S. (2005). Atrial fibrillatino in dogs with and without structural of functional cardiac disease: a retrospective study of 109 cases. Journal of Veterinary Cardiology 7 (2), 75-83.

Moe G.W., Howard R.J., Grima E.A., Armstrong P.W. (1995). How does intermittent pacing modify the response to rapid ventricular pacing in experimental heart failure? Journal of Cardiac Failure 1 (3), 223-228.

Oyama M.A., Reynolds C.A. (2014). Ventricular arrhythmias in dogs. In: Bonagura J.D., Twedt D.C. (editors). Kirk's Current Veterinary Therapy $X V$. First edition, Elsevier Saunders, St. Louis, 745-747.

Pariaut R., Santilli R.A., Moïse N.S. (2014). Supraventri- cular tachyarrhythmias in dogs. In: Bonagura J.D., Twedt D.C. (editors). Kirk's Current Veterinary Therapy XV. First edition, Elsevier Saunders, St. Louis, 737-744.

Perego M., Ramera S., Santilli R.A. (2012). Isorhytmic atrioventricular dissociation in labrador retrievers. Journal of Veterinary Internal Medicine 26 (2), 320-325.

Philips D.E., Harkin K.R. (2003). Hypothyrodism and myocardial failure in two great Danes. Journal of the American Animal Hospital Association 39 (2), 133-137.

Riegger A.J.G., Liebau G. (1981). The renin-angiotensinaldosterone system, antidiuretic hormone and sympathic nerve activity in an experimental model of congestive heart failure in the dog. Clinical Science 62 (5), 465-469.

Sanderson S.L. (2006). Taurine and carnitine in canine cardiomyopathy. Veterinary Clinics of North America: Small Animal Practice 36 (6), 1325-1343.

Santilli R.A. (2000). Orthodromic incessant atrioventricular reciprocating tachycardia in a dog. Journal of Veterinary Cardiology 2 (1), 25-29.

Santilli R.A., Perego M., Crosara S., Gardini F., Bellino C., Moretti P., Spadacini G. (2008). Utility of 12-lead electrocardiogram for differentiating paroxysmal supraventricular tachycardias in dogs. Journal of Veterinary Internal Medicine 22 (4), 915-923.

Santilli R.A., Ramera L., Perego M., Moretti P., Spadacini G. (2014). Radiofrequency catheter ablation of atypical atrial flutter in dogs. Journal of Veterinary Cardiology 16 (1), 9-17.

Santilli R.A., Spadacini G., Moretti P., Perini A., Tarducci A., Crosara S., Salerno-Uriarte, J.A. (2006). Radiofrequency catheter ablation of concealeed accessory pathways in two dogs with symptomaticc atrioventricular reciprocating tachycardia. Journal of Veterinary Cardiology 8, 157-165.

Shinbane J.S., Wood M.A., Jensen D.N., Ellenbogen K.A., Fitzpatrick A.P., Scheinman M.M. (1997). Tachycardiainduced cardiomypathy: a review of animal models and clinical studies. Journal of the American College of Cardiology 29 (4), 709-915.

Umana E., Solares C.A., Alpert M.A. (2003). Tachycardiainduced cardiomyopathy. The American Journal of Medicine 114 (1), 51-55.

Ware W.A. (2013a). Overview of electrocardiography. Cardiovascular Disease in Small Animal Medicine. Fourth edition, Manson Publishing, Londen, 47-67.

Ware W.A. (2013b). Myocardial diseases of the dog. Cardiovascular Disease in Small Animal Medicine. Fourth edition, Manson Publishing, Londen, 280-292.

Ware W.A. (2014). Myocardial Disease of the Dog. In: Nelson R.W., Couto C.G. (editors). Small Animal Internal Medicine. Fifth edition, Elsevier Mosby, St. Louis, 130-144.

Wess G., Mäurer J., Simak J., Hartmann K. (2010). Use of Simpson's method of disc to detect early echocardiographic changes in Doberman Pinschers with dilated cardiomyopathy. Journal of Veterinary Internal Medicine 24 (5), 1069-1076.

Wright K.N., Atkins C.E., Kanter R. (1996). Supraventricular tachycardia in four young dogs. Journal of the American Veterinary Medical Association 208 (1), 75-80.

Wright, K.N. (2015). Supraventricular tachyarrythmias. In: Silverstein D.C., Hopper K. (editors). Critical Care Medicine. Second edition, Elsevier Saunders, St. Louis, 250254.

Zupan I., Rakovec P., Budihna N., Brecelj A., Koželj M. (1996). Tachycardia induced cardiomyopahty in dogs; relation between chronic supraventricular and chronic ventricular tachycardia. International Journal of Cardiology $56(1), 75-81$. 